Ma Carmen África Vidal Claramonte

Traducción y literatura translingüe Voces latinas en Estados Unidos 


\section{Ediciones de Iberoamericana}

\section{0}

Consejo EDITORIAL:

Mechthild Albert

Rheinische Friedrich-Wilhelms-Universität, Bonn

Daniel Escandell Montiel

Universidad de Salamanca

Enrique García-Santo Tomás

University of Michigan, Ann Arbor

Aníbal González

Yale University, New Haven

Jorge J. Locane

Universitetet i Oslo

Klaus Meyer-Minnemann

Universität Hamburg

Daniel Nemrava

Palacky University, Olomouc

Emilio Peral Vega

Universidad Complutense de Madrid

Janett Reinstädler

Universität des Saarlandes, Saarbrücken

Roland Spiller

Johann Wolfgang Goethe-Universität, Frankfurt am Main 


\title{
Traducción y literatura translingüe
}

Voces latinas en Estados Unidos

\author{
Ma Carmen África Vidal Claramonte
}

Prefacio de Georges L. Bastin 


\section{Este libro es resultado del Grupo de Investigación Reconocido TRADIC}

Cualquier forma de reproducción, distribución, comunicación pública o transformación de esta obra solo puede ser realizada con la autorización de sus titulares, salvo excepción prevista por la ley. Diríjase a CEDRO (Centro Español de Derechos Reprográficos) si necesita fotocopiar o escanear algún fragmento de esta obra.

(www.conlicencia.com; 917021970 / 9327204 47)

\section{Derechos reservados}

(C) Iberoamericana, 2021

Amor de Dios, 1 - E-28014 Madrid

Tel.: +34914293522 - Fax: +34914295397

(c) Vervuert, 2021

Elisabethenstr. 3-9 - D-60594 Frankfurt am Main

Tel.: +49695974617 - Fax: +49695978743

info@iberoamericanalibros.com

www.iberoamericana-vervuert.es

ISBN 978-84-9192-199-8 (Iberoamericana)

ISBN 978-3-96869-128-2 (Vervuert)

ISBN 978-3-96869-129-9 (e-Book)

Depósito Legal: M-19437-2021

Diseño de la cubierta: a. f. Diseño y Comunicación

Ilustración de cubierta: Muro de frontera entre Estados Unidos y México (Joe Farah, Shutterstock)

Impreso en Espańa

Este libro está impreso íntegramente en papel ecológico sin cloro. 


WhERE You From?
Gina Valdés
Soy de aquí
y soy de allá
from here
and from there
born in L.A.
del otro lado
y de éste
crecí en L.A.
y en Ensenada
my mouth
still tastes
of naranjas
con chile
soy del sur
y del norte
crecí zurda
y norteada
cruzando fron
teras crossing
San Andreas
Tartamuda
Y mareada
where you from?
soy de aquí
y soy de allá
I didn't build
this border
that halts me
the word fron
tera splits
on my tongue.


